\title{
Políticas públicas:
}

\section{formação de gestores governamentais em tempos de mudança}

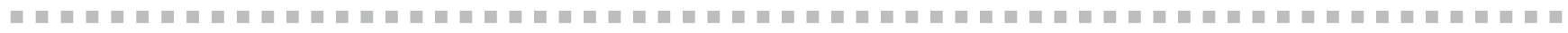

Eda Castro Lucas de

A de políticas públicas de formação de gestores governamentais. Para tal, foram utilizados os fatores da teoria de institution building, apresentados no modelo de Esman, acrescidos de outros fatores de natureza político-cultural e administrativa, peculiares ao aparato estatal brasileiro. Com base nesse marco teórico, adaptado às políticas públicas, foram trabalhados elementos básicos que possibilitam verificar as tendências e o processo de institucionalização das mesmas. Foram apresentadas algumas dificuldades para o processo de institucionalização dessas políticas, bem como recomendadas algumas propostas para que as mesmas adquiram sentido de função social, sejam aceitas pela sociedade, estabeleçam um sistema de relações a ser seguido e exerçam influência em seu contexto, isto é, institucionalizem-se.

\section{Souza}

Palavras-Chave: políticas públicas, institucionalização, formação de gestores.

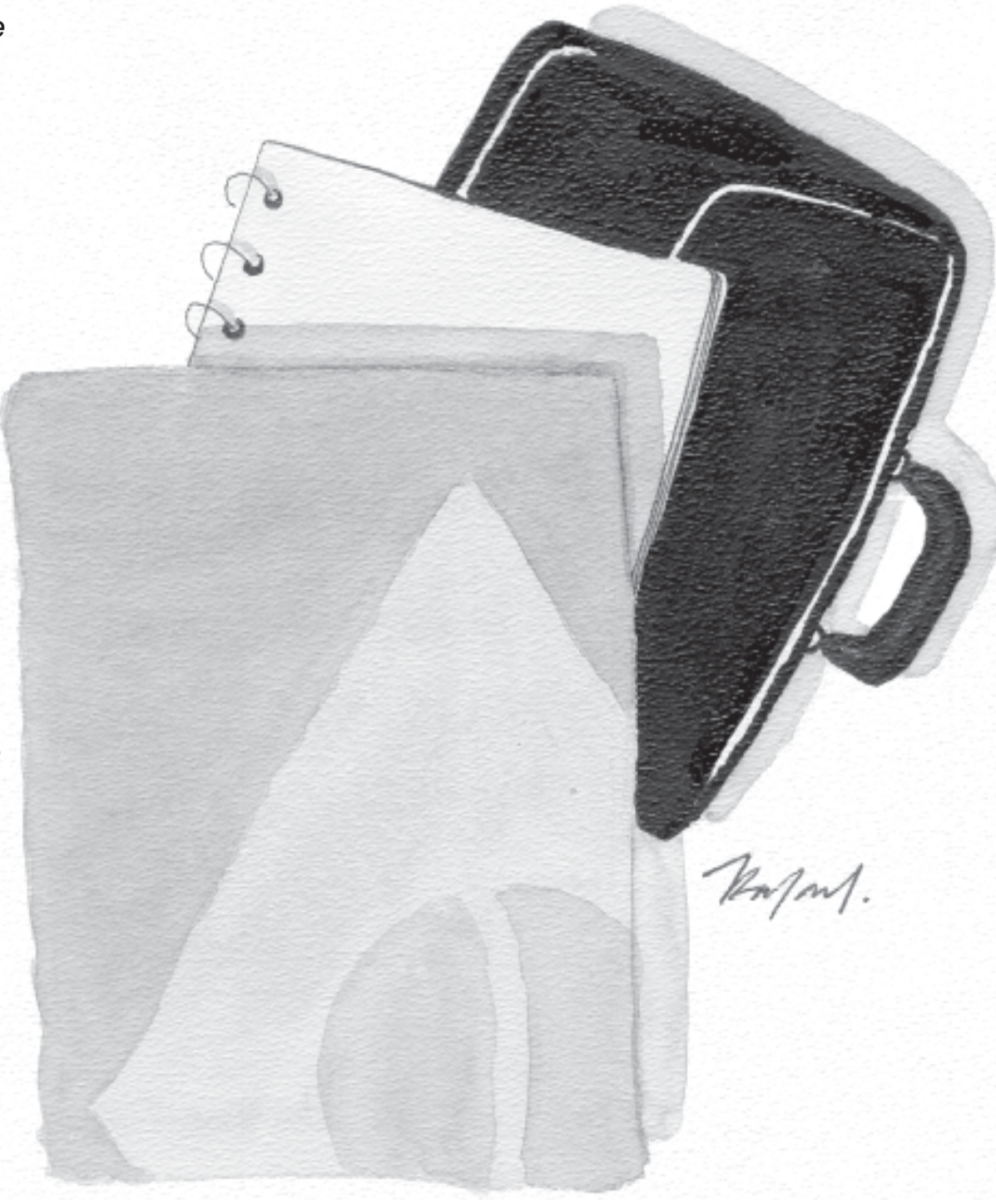




\section{Introdução}

Este estudo se propõe a provocar uma reflexão a respeito de políticas públicas de formação de gestores, ${ }^{1}$ enquanto desenvolvimento de novas capacidades (Ardoino, 1971), ou seja, políticas de desenvolvimento e aperfeiçoamento dos conhecimentos, das capacidades e dos comportamentos dos responsáveis pela gestão governamental.

Essas políticas são importantes no sentido de que constituem um dos instrumentos para tornar o aparato estatal uma das instâncias de representação de interesses universais da sociedade. Daí surge a necessidade de um modelo gerencial efetivo para a sua operacionalização ordenada, segundo uma escala de autoridade, levando a uma relação de autonomia de um corpo de funcionários em frente da sociedade. Relações essas que, cada vez mais, "requerem um forte crescimento nas disponibilidades de capacidade administrativa" (Kliksberg, 1988).

Além do mais, a década de 90 tem sido inovadora e, até certo ponto, revolucionária no que diz respeito à prática da gestão. Assim, na gestão de várias áreas, foram criadas novas estratégias para produzir respostas aos problemas que têm surgido com a transformação dos contextos nacional e mundial (Motta, 1994). A função gerencial e a organização do trabalho delinearam um novo perfil de competências e tecnologias de gestão.

Este trabalho tem como objetivo desenvolver uma análise sobre a institucionalização das políticas públicas para a formação de gestores governamentais, voltada para suas dimensões internas e, principalmente para os contextos, nos quais essas dimensões podem levar a sucessos ou fracassos.

Nesse sentido, os fatores da teoria de institution building, apresentados no modelo de Esman (1966), acrescidos de outros fatores de natureza política, administrativa e cultural, dos cenários onde se desenvolvem essas políticas públicas, foram

${ }^{1}$ Gestor membro da carreira de Especialista em Políticas Públicas e Gestão Governamental. considerados as bases conceituais deste estudo.

\section{Políticas públicas: institucionalização}

Normalmente o termo política pública é empregado para indicar a atividade ou o conjunto delas, que tem como ponto de referência o Estado, núcleo de tais ações.

Institucionalização, segundo Selznick (1971), é um processo no qual são determinadas modificações de uma organização, através do tempo, refletindo sua evolução histórica, seus componentes, seus interesses e o modo como interage com o seu meio ambiente. Sob esse ângulo, uma organização pode transformar-se em instituição se preencher certas condições, tais como autonomia e capacidade de influir no meio ambiente.

Institucionalização, portanto, passa a ser o processo no qual as organizações se transformam em instrumentos de criação e difusão de valores, que possibilitam mudanças sociais (Souza, 1996). A institucionalização é o momento morfológico da organização, quando se dá, segundo Lourau (1995), a síntese dialética da organização, do plano racional, do programa, das determinações materiais e formais.

Considerando que uma organização pode ser o produto de uma política, ou o locus de sua elaboração e implementação, pode-se dizer, então, que uma política institucionaliza-se quando infunde valores, além das exigências técnicas da tarefa.

Uma política pública institucionaliza-se quando difunde valores que possibilitam mudanças e cumpre objetivos sociais. As políticas públicas, nesse caso, passam a simbolizar as aspirações da sociedade e a atender suas demandas.

Uma política pública institucionaliza-se quando é internalizada pelo seu ambiente interno e externo, seus padrões de ação são aceitos pelo contexto, é adaptável às mudanças, possui um conjunto normativo e estabelece um consenso em torno de seus objetivos, que são incorporados ao contexto social.

Em síntese, uma política pública quando adquire sentido de função social é aceita pela sociedade, estabelece um sistema de relações a ser seguido, torna-se influente em seu contexto, passa a ser institucionalizada. 


\section{Modelo para elaboração e implementação de políticas públicas}

O modelo de Esman (1966), adotado neste estudo, contém elementos considerados básicos para o processo de desenvolvimento institucional, visto como uma perspectiva de mudança social. Ou seja, as variáveis institucionais reunidas em cinco grupos: Liderança, Doutrina, Programa, Recursos e Estrutura Interna, os vínculos interdependências existentes entre as instituições e outros segmentos relevantes da sociedade - e as transações, consideradas as trocas de bens e serviços e a permuta de poder e influência com o meio ambiente, através de certos elementos mediadores (Souza, 1996). Para Esman, por meio de um corpo de variáveis e seus indicadores, é possível verificar a tendência e identificar o caráter institucional da organização.

Numa perspectiva mais global, política pública é considerada neste trabalho como o conjunto de atividades ou ações com perspectivas de provocarem mudança social, dirigida ou planejada. Ou ainda, um sistema de regras, objetivos, instrumentos técnicos, planejados como meio para finalidades definidas, além de ser produto das pressões e necessidades sociais. As políticas podem ser comparadas às organizações, onde as dimensões comuns mais significativas são a técnica, destinada a alcançar os objetivos, e a subjetiva onde estão as relações que devem satisfazer às necessidades e às demandas sociais. Nessa linha, as políticas, tais como as organizações, podem admitir elementos básicos que possibilitam verificar suas tendências e o seu grau de institucionalização.

Tendo em vista essas considerações e o propósito deste trabalho, o modelo de Esman foi adaptado para o processo de análise, elaboração e implementação de políticas públicas e suas variáveis definidas como se segue.

\section{LIDERANÇA}

A liderança é exercida pelo grupo de pessoas que elabora e dirige as ações internas e externas de operacionalização da política, essencialmente pelos atores que detêm o poder de decisão. Quando falta liderança, as políticas enfraquecem diante das pressões oportunistas. A viabilidade política, o status profissional e a competência dos atores envolvidos no processo, a distribuição de papéis e a continuidade são variáveis de liderança.

\section{DOUTRINA}

Doutrina é a linha de ação da política, o conjunto de valores, os objetivos a serem seguidos, os métodos operacionais a serem adotados, o parâmetro para o estabelecimento do programa. No processo de institucionalização de uma política, o principal objetivo é a incorporação e a disseminação de valores sociais para o ambiente interno e externo onde a mesma se desenvolve. Com essa variável, a política é vista como a personalização de valores que a sociedade passa a adotar.

O corpo de valores da política deve ter especificidade, estar vinculado às normas existentes, ter relação com as preferências e prioridades da sociedade. Para que a política se institucionalize, esses valores devem ter definição clara, adequada ao meio, sentido de inovação, perspectiva de futuro e papel destacado nas transações internas e externas da organização.

\section{PROGRAMA}

Programa é um conjunto de ações ligado ao desempenho das funções e serviços que constituem os produtos da política. É o conjunto de atividades previstas para serem desenvolvidas, os produtos esperados, a tradução do corpo de valores em ação. Isso envolve a formulação, o conteúdo e a execução do programa, além de um conjunto de escolhas sobre como serão aplicados os recursos e que fluxo de produtos a política deverá propiciar. O programa deverá ser coerente, estável, viável, e atender às necessidades.

\section{RECURSOS}

Os recursos constituem-se no conjunto de entradas financeiras, humanas, informacionais, físicas e científicotecnológicas para a execução da política. Essa variável diz respeito não só aos recur- 


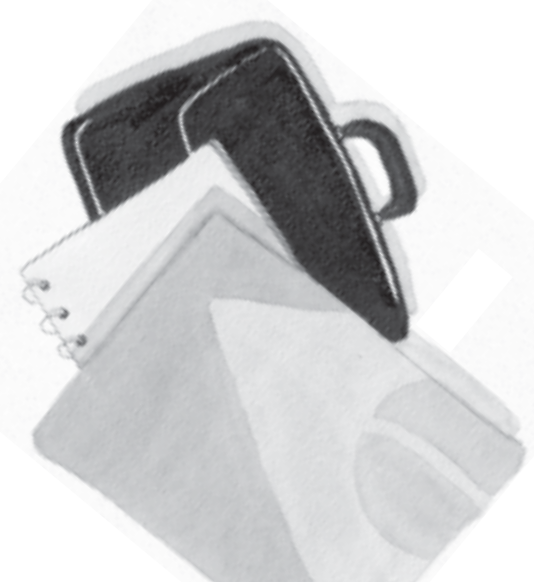

sos disponíveis como às fontes de onde provêm. Considerando esses dois aspectos que podem ou não viabilizar as políticas, é necessário assegurar a disponibilidade dos recursos e vincular à política as fontes de onde eles são obtidos. Os resultados da política e sua eficácia podem ser afetados pela habilidade dos atores em mobilizar recursos, identificar e negociar com as fontes de onde eles provêm.

\section{ESTRUTURA}

A estrutura interna é a disposição dos recursos em padrões formais e informais de autoridade, divisão de responsabilidades entre os diferentes atores e unidades que compõem a política, canais de comunicação e meios de resolver conflitos e formular consenso sobre prioridades, políticas e procedimentos. Representa o locus onde o poder é exercido, determina o fluxo de informação que envolve as decisões (Hall, 1984).

A estrutura é definida como os processos internos às organizações, ou seja, - locus da política, responsáveis pela eficiência e pela eficácia da implementação das mesmas. É importante que a estrutura de suporte às políticas seja identificada, consistente, adaptável, simples, contribuindo para a eficiência das políticas e os graus de decisão.

A estrutura interna pode até ser complexa, mas não confusa. Seu funcionamento é pleno e flexível para a adaptação de seus programas, deve ser equilibrada em seus diversos níveis e efetiva em suas ações.

\section{VÍNCULOS}

Uma das características para que uma política se institucionalize é manter-se em constante interação com o meio ambiente. Essas interações podem ser chamadas de vínculos, que são as interdependências existentes entre as políticas e os outros segmentos relevantes para o seu desenvolvimento e para a sociedade. As transações das diferentes políticas ou das políticas com instituições são realizadas pelos vínculos ou elos institucionais, por intermédio dos quais as políticas desenvolvem relações de intercâmbio com o seu contexto.

\section{TRANSAÇÕES}

As organizações têm a característica de não existirem isoladamente, há interdependência entre as mesmas, o que é de grande relevância para a sociedade. Esse processo envolve trocas de bens e serviços e a permuta de poder e influência com o meio ambiente - transações. Partindo do princípio que as políticas públicas podem ser comparadas com as organizações, as transações devem ser consideradas para a elaboração e implementação das políticas.

Nesse sentido, o propósitos das transações são:

- obtenção de suporte para as políticas;

- troca de recursos necessários para a operacionalização das políticas;

- estruturação do meio ambiente, no qual se desenvolvem as políticas públicas;

- transferência de normas e valores, com base nas quais as transações podem ser direcionadas para a introdução de novos padrões de ação, com os quais as políticas podem mudar as pessoas, outras políticas e o próprio meio.

\section{CULTURA POLIITICO-ADMINISTRATIVA}

Aos aspectos culturais que embasam o relacionamento entre o Estado e a sociedade brasileira devem ser acrescentados, também, como arraigados no contexto político-institucional, o clientelismo, o corporativismo e uma cultura conformista que aceita o favoritismo e a corrupção, valores esses que se estendem ao aparato burocrático.

Envoltos nessas práticas tradicionais que favorecem interesses particulares, o Estado brasileiro caracteriza-se pelo intenso e generalizado patrimonialismo que determina as relações entre os dirigentes políticos e os quadros do serviço público, fa- 
zendo com que os servidores, em grande parte, sirvam aos interesses políticoconjunturais dos dirigentes (Souza, 1997).

O corporativismo estatal, em que as corporações lutam, na maioria das vezes, pelos interesses próprios e não públicos, faz surgir estamentos fechados, geradores de suas próprias políticas públicas, que detêm notável capacidade de manipular dados, de influenciar meios de comunicação e a opinião pública. Dificilmente uma política pública que busque implementar algo novo, sobretudo o que ameace o campo de força e o poder desses miniestados, é institucionalizada ou mesmo sobrevive às suas reações.

$\mathrm{Na}$ estrutura de poder clientelista do Estado brasileiro, o público ${ }^{2}$ é substituído por outros mecanismos de autoridade e de competência política. Há um conflito da sociedade, que privilegia o espontâneo, as relações pessoais, os laços de integração clientelar, versus tentativas racionalistas de articular o público, por intermédio de uma expressão burocrática.

A cultura política tradicional, além de reativa à valorização do estatal e do público, é acrescida, no plano da reflexão científico-social, de modelos que, mesmo sendo opostos, coincidem na ausência de uma resposta ao problema da organização do Estado. Esse quadro possibilita explicar a falta de condições culturais para o desenvolvimento de políticas públicas de formação de gestores com sucesso.

Outra característica da cultura políticoadministrativa brasileira é a descontinuidade das ações governamentais que provocam, entre outras coisas, a rotatividade dos dirigentes, estende-se aos programas e projetos que sustentam as políticas públicas, desestabilizando-as e comprometendo os seus processos de institucionalização. Essa descontinuidade tem marcado, significativamente, os processos de reforma administrativa que, por esse motivo, não atingem, na maioria das vezes, o núcleo dos problemas da máquina estatal, tornandose inconclusos.

\section{Políticas públicas de formação de gestores}

No contexto das idéias e da concepção das políticas públicas e, em particular, no contexto das políticas de formação de gestores governamentais, observa-se que seus desenvolvimentos institucionais e, conseqüentemente, sua viabilização, estão subordinados, não apenas aos elementos formadores da cultura de seus contextos, como também, às características básicas de suas sociedades; às relações políticas em vigor no momento histórico de sua elaboração e implementação; ao papel a ser desempenhado pelos atores envolvidos, $e$ às políticas públicas do aparato estatal.

Com isso, pensar em políticas de Administração Pública, como a de formação de gestores do Estado, inclui a realização de uma análise do contexto políticoinstitucional, em que essas políticas se desenvolvem, a vontade política do governo, e outras medidas adicionais como a implantação de:

- sistema do mérito;

- plano de carreira;

- sistema de capacitação de recursos humanos para o setor público;

- política salarial;

- alocação de recursos para a formação;

- condução de projetos para a reorganização do aparato estatal.

Com efeito, levando em conta esses condicionantes, é possível trabalhar a idéia de políticas de formação de gestores, especialistas em políticas públicas e gestão governamental, que podem contribuir de forma importante para recuperar a capacidade de ação do aparelho burocrático do Estado.

Torna-se conveniente destacar que a institucionalização dessas políticas depende de condições sociais, políticas e administrativas de seu meio, tais como:

- a existência de um sistema de carreira efetivo para o setor público;

- um sistema de formação e capacitação de gestores, fundado sob a pluralidade do conhecimento, que tem a missão de possibilitar o exercício de funções múltiplas, entre as quais predomina o controle do aparelho administrativo;

- o modelo do Estado;

- o interesse das elites dominantes;

- uma forte liderança político-administrativa representada, inicialmente pela vontade política dos decisores do processo político.

\footnotetext{
$\overline{2}$ Público, nesse caso, é considerado a coisa pública, aquilo que é da ou para a sociedade.
} 


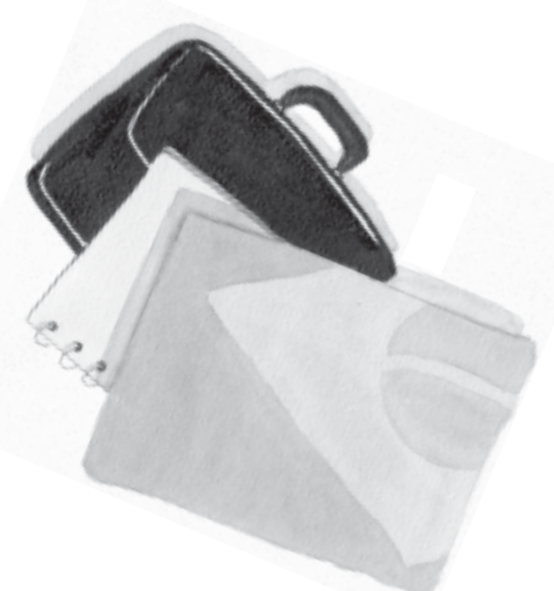

Acrescenta-se a isso a autonomia administrativa e orçamentária; os vínculos principalmente com os organismos que representam o poder; um programa claro, prático e objetivo; uma doutrina que engloba um corpo de valores representativo do Estado e da sociedade.

É oportuno observar que algumas políticas que possibilitaram o desenvolvimento de projetos de capacitação administrativa para uma função pública em plena reorganização e um Estado em reconstrução, ou seja, que vieram no bojo de uma reforma administrativa, adquiriram uma identidade, internacionalizando-se pela excelência de seus resultados e pelo papel que os egressos de seus programas representam junto à sociedade, como é o caso da Ecole Nationale d'Administration (ENA) francesa (Souza, 1996).

Aqui convém lembrar que a ENA, na França, em 1945, "foi criada em um contexto histórico-institucional de efetivas transformações sociais, políticas, econômicas e administrativas. Nasceu não só de uma evolução cronológica, mas da vontade de um povo e da necessidade fundamental de reformulação do Estado e de conseqüentes mudanças na função pública, principalmente de seus quadros dirigentes" (Souza, 1997). Foi instituída, portanto, no bojo de uma audaciosa reforma administrativa, vindo ao encontro de uma necessidade de abertura da função pública, modificando sua arquitetura, além de introduzir-lhe um processo mais democrático.

A dificuldade de institucionalização de políticas que implementem, no Brasil, programas de formação de agentes governamentais encontra explicações no quadro político-institucional da transição democrática e da crise econômica, acoplado a um aparato estatal desarticulado, incapaz de atender às demandas sociais.
Deve-se considerar, também, que a institucionalização efetiva dessas políticas não é compatível com um Estado patrimonialista e com uma administração pública caracterizada pelo clientelismo e pelo corporativismo.

Rever essa cultura e tentar quebrar o ciclo do personalismo e do insulamento burocrático que a compõem é, pois, condição para que políticas públicas de formação de gestores governamentais que vêm em nome da ética pública, do mérito, do profissionalismo e da eficácia, institucionalizem-se.

As mudanças de cenário político-econômico e organizacional, a descontinuidade administrativa e a falta de comprometimento com a concepção das políticas e de seus programas de formação de gestores desestabilizam-se, levando-as à extinção.

O fator tempo passa a ser fundamental na institucionalização dessas políticas, que necessitam de um período hábil para se desenvolver, de modo que sejam possíveis suas consolidações, a formação de identidade, a criação de um corpo sólido de valores e a busca de seus primeiros objetivos.

À luz das categorias do modelo conceitual de Esman (1966) e do modelo deste trabalho, dificilmente políticas públicas para a formação de gestores governamentais institucionalizar-se-iam sem estarem centradas em dispositivo composto de:

- um sistema de preparação para o concurso de entrada que o tornaria democrático;

- um sistema de carreira que garantisse aos egressos ascensão progressiva, assim como uma remuneração compensatória, sem o que é difícil motivar e atrair pessoas competentes para o curso;

- um programa flexível, atualizado, voltado para uma escola de aplicação;

- continuidade dos responsáveis pela Escola que deverão liderá-la, preservar seus objetivos, implementar seus valores, criar e manter seus vínculos, levar o curso adiante.

\section{Institucionalização de políticas de formação de gestores para 0 aparato estatal}

No Brasil, provavelmente, são inúmeras as dificuldades e a falta de condições 
para a institucionalização de políticas de formação de especialistas em políticas públicas e gestão do Estado. No entanto, na tentativa de reduzir a complexidade e viabilizar este estudo, foram priorizados e analisados alguns fatores, possivelmente os mais responsáveis pelo impedimento do desenvolvimento institucional de programas de formação desses administradores.

Por um lado, as ações do mundo moderno, o desenvolvimento das tecnologias e os desafios do futuro impulsionam a busca de novos horizontes, imprimem novas direções ao conhecimento, afetando a formação do homem, as condições de trabaIho, as relações institucionais, a empregabilidade, envolvendo direta ou indiretamente os diversos atores sociais, como o governo e as instituições.

A construção de novos modelos gerenciais e, portanto, a elaboração de políticas de formação para o setor público deverão enfocar a "especialização flexível", a divisão menos acentuada do trabalho, a integração mais pronunciada de funções, maior impulso para a formação continuada, ou seja, uma política de profissionalização de $\mathrm{RH}$.

Nesse contexto, é necessário fazer frente, não de forma individual, mas como um problema também das organizações e dos governos, às oportunidades e às ameaças que a era da alta tecnologia nos apresenta, em princípio: deve:

Quanto à ética de comportamento, que

- harmonizar as relações indivíduo/ sociedade/natureza, sintetizada no respeito, na solidariedade e na cooperação.

Quanto ao mundo do trabalho, caracterizado:

- pelas rápidas mudanças e pela urgente preparação para enfrentar os descompassos de qualificação advindos dessas mudanças;

- pelas demandas de formação;

- pela qualificação e competência que exigem um estado de prontidão e aprendizagem constante;

- pela formação continuada;

- pela flexibilidade qualitativa da mãode-obra;

- pela oposição à rotina e às qualificações obtidas por imitação ou repetição, tornando-se cada vez mais importante a formação do trabalhador "intelectual".

\section{Quanto ao mundo do indivíduo:}

- pela necessidade de programas de qualificação nos quais as dificuldades e os talentos individuais encontram espaço para manifestação;

- pela complementação daquilo que a racionalidade e o saber técnico e metodológico oferecem para a formação profissional. Ou seja, pelo reconhecimento e visualização das condições formadoras do contexto vivencial, das emoções, da memória coletiva e dos caminhos próprios de aprendizagem, passo primordial para o aprimoramento da auto-estima e da quebra de concepções desestimulantes aos novos e contínuos aprendizados;

- pela empregabilidade - capacidade de obter um emprego, ou ainda, qualidade de ser empregável, incluindo, dessa forma, preparação e dedicação, aliadas a uma expectativa, interesse ou estímulo - o que requer uma parceria transparente e de compromisso entre as organizações e o indivíduo.

\section{Quanto à aprendizagem:}

- pela necessidade de um sistema de seleção, recrutamento e formação, apoiado em políticas públicas consistentes, como condição fundamental para o fortalecimento da capacidade administrativa;

- por uma base da inovação organizacional, através de incentivo às múltiplas formas e conteúdos de aprendizagem;

- pelo desenvolvimento de comportamentos criativos, inovadores, adaptáveis, e pela formação de novas atitudes em frente das relações entre o ritmo do progresso técnico e a intervenção humana, formando pessoas capazes de evoluir, adaptar-se a um mundo em rápida mudança e serem agentes de mudança e controle da mesma;

- pela elaboração de projetos pedagógicos voltados para as necessidades práticas e para o desenvolvimento econômico do país.

Quanto às experiências inovadoras:

- educação contínua e não apartada do mundo do trabalho. A adequação propositiva a novos cenários implica assumir uma postura de educação antecipatória na qual se eleja a revisão crítica dos conteúdos e procedimentos de formação profissional, o estabelecimento de parcerias plurifacetadas, o investimento em pesqui- 


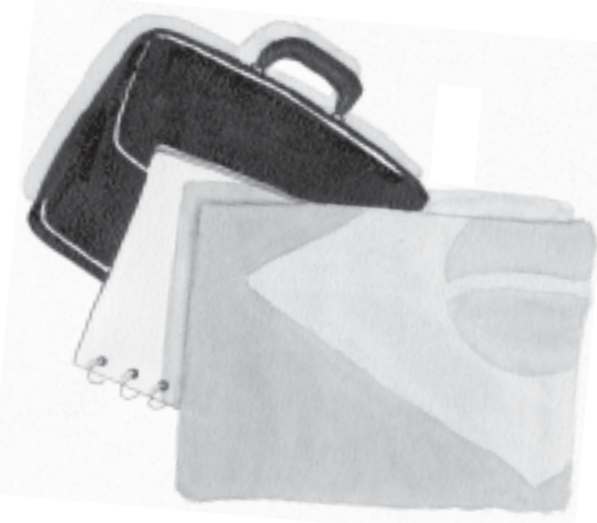

sas, como um arcabouço sólido de sobrevivência cooperativa e competitiva;

- empenho consistente em rejeitar concepções arcaicas, sem que isso acarrete o abandono de valores e princípios tradicionais, inerentes a cada organização ou parceiro envolvido. A mudança dos paradigmas formadores não deve levar a uma perda de identidade e sim a uma reconstrução ousada e criativa da natureza instrumental dos processos pedagógicos;

- o desafio a ser enfrentado não se restringe a esforços particulares e isolados. Mas devem envolver distintas instâncias, em conexão com as políticas e recursos governamentais, possibilitando mais organicidade dos investimentos financeiros e uma legitimidade política, acrescentando mais qualidade social à elaboração de alternativas conjuntas.

A sociedade do futuro tende a ser uma sociedade instruída, ou seja, aquela que se organiza, fundamentalmente, a partir da aplicação dos conhecimentos de seus cidadãos. O centro de gravidade social desloca-se para o "trabalhador intelectual", e o acesso aos empregos e a uma carreira exigem maior nível de formação, atualização e aperfeiçoamento. Nesse sentido, as políticas de formação deverão ser um processo permanente de enriquecimento do conhecimento, de capacidade técnica e, essencialmente, de estruturação da pessoa e das relações entre indivíduos, grupos e nações, um instrumento de promoção do ser humano (Drucker, 1993).

Visto desse ângulo, uma das metas prioritárias do governo deveria ser a formação de gestores do Estado, recursos humanos capacitados para a resolução de problemas complexos, responsáveis e comprometidos com a sociedade, propulsores das mudanças necessárias para adaptar o aparato estatal às exigências da sociedade democrática. Conduzir a mudança, segundo Motta (1997), "é gerenciar o hiato entre a percepção da realidade vivida e a promessa da nova ordem". Implica que os administradores conheçam, ou meIhor, compreendam o contexto organizacional no qual se desenvolve a mudança, bem como tenham capacidade e condições para obter e administrar recursos e superar as resistências e os conflitos.

Por outro lado, na cultura política brasileira, por razões religiosas, ideológicas, culturais, históricas e políticas, existe uma débil legitimação das instituições estatais. O modelo de aparato administrativo eficiente, que forma uma espécie de coluna vertebral do Estado como corporação do público, é uma idéia pouco legitimada. Em geral, no Brasil vivencia-se o político e o público na base da desconfiança, e os laços de articulação social desenvolvem-se no âmbito do privado (Matta, 1990).

O Brasil tem apresentado dificuldades de consolidação, principalmente no aspecto da definição de uma administração pública eficiente, capaz de arbitrar os conflitos intercorporativos na sociedade (Souza, 1997).

A atuação administrativa do Estado tem sido lenta e insatisfatória para atender às demandas da sociedade, principalmente àquelas advindas do processo democrático, o que leva a urgência da reforma do aparelho burocrático, e de seu modelo administrativo. Hoje, não se pode pensar em uma administração passiva, rotineira, baseada em uma estrutura própria de outro momento histórico.

De fato, além desses, outros fatores, como as descontinuidades advindas das mudanças político-administrativas; a falta de uma liderança, ativamente engajada na elaboração de políticas de formação, em sua implementação e na execução dos seus objetivos; a falta de condições para desenvolver programa inovadores de administração; a carência de vínculos favoráveis e fortes com instituições e órgãos dos Poderes do Estado; a não-autonomia administrativo-orçamentária; a falta de estruturas organizacionais adequadas interferem na evolução das políticas de formação de administradores para o Estado, provocando, muitas vezes, pontos de inflexão que mudam o rumo de suas trajetórias, dificultando o cumprimento de seus objetivos.

Esse insucesso pode ser entendido como o não cumprimento dos propósitos para os quais foram criadas as políticas, 
bem como, a impossibilidade das mesmas em não se institucionalizarem, considerando a dimensão sociológica, isso é, tornarem-se provedoras de valores de estabilidade social, coesão e integração (Selznick, 1971). Ou, ainda, dentro de uma perspectiva mais geral, de serem organismos vivos que evoluem com o tempo, incorporam, incentivam e protegem relacionamentos normativos, padrões de ação, funções, desempenhos e serviços considerados de relevância social para o Estado e a sociedade (Esman, Bruhns, 1965).

\section{Conclusão}

O fato de as políticas de formação de gestores governamentais do Brasil terem encontrado dificuldade em se institucionalizarem, e este estudo apresenta alguns fatores responsáveis por isso, especialmente os relativos à cultura políticoadministrativa, possibilita recomendações de algumas propostas.

Em primeiro lugar, torna-se conveniente tomar em consideração os fatores aqui apresentados como responsáveis pela dificuldade de institucionalização de políticas de formação de gestores governamentais e transformá-los em condicionantes da possibilidade de sucesso para as mesmas, que viriam a formar altos funcionários, como uma estratégia para a reforma do Estado.

Em segundo lugar, que a proposta seja de políticas de cunho democrático no sentido de serem oferecidas oportunidades de ingresso a candidatos de todo o país, com iguais oportunidades. Para tanto, deveriam ser estabelecidos acordos com universidades e centros de preparação para desenvolver cursos preparatórios descentralizados e coordenados pela escola, criada para desenvolver os programas de formação de gestores, que se transformaria no núcleo de uma rede de ensino.

Em terceiro lugar, essas políticas devem conceber organizações para a formação com característica de escolas de aplicação, nas quais o estágio obrigatório ocupa papel considerável na formação dos alunos, bem como possibilita uma maior integração com a máquina burocrática. Teriam os futuros responsáveis pela administração pública uma formação profissional privilegiada pelos exercícios práticos, fundamentada na ética e nos valores da res publica, não só no período de escolaridade, mas, também, na observação concreta do cotidiano.

Em quarto lugar, as políticas seriam pluralistas quanto à sua orientação curricular, distribuindo equilibradamente as disciplinas técnicas e de formação geral. Propiciando analisar conscientemente os problemas relativos à ação administrativa; elaborar propostas de políticas públicas operacionais, inovadoras e viáveis; enfocar questões sociais, políticas e administrativas em distintas dimensões.

Em quinto lugar, as políticas viriam com o apoio e o acompanhamento do governo, acopladas a um projeto nacional de desenvolvimento, a uma concepção de Estado e a outras ações administrativas, essenciais a sua implementação.

Em sexto e último lugar, essas políticas de formação seriam responsáveis pela formação de um corpo de gestores governamentais generalistas e especialistas em políticas públicas que fossem agentes de mudança, sensíveis às implicações sociais e políticas das ações administrativas e ao sentido do serviço público, elementos estratégicos para atuar na redefinição e modernização do Estado.

Dentro de uma concepção dinâmica, as políticas públicas de formação de gestores deverão ter: objetivos conhecidos e legitimados, mudanças e conflitos considerados, formas organizacionais e jurídicas claras, planos racionais, programas viáveis, determinações materiais e formais definidas, percepção dos diversos atores envolvidos no processo considerado.

Nessa linha, as análises realizadas para elaborar essas políticas visarão apreender o comportamento da sociedade e do aparelho do Estado, suas relações internas e externas, isto é, realizarão uma verdadeira intervenção socioinstitucional.

Aqui cabe ressaltar a importância de as políticas públicas serem compatíveis com o contexto social, político, econômico e tecnológico. Além de acompanharem e se adequarem ao processo de mudança social e estarem comprometidas com a busca de novos paradigmas que visem eliminar as disfunções e distorções políticas, culturais e administrativas. 


\section{Referências bibliográficas}

ARDOINO, J. Psicologia da educação : na universidade e na empresa. São Paulo : Ed. da USP, 1971.

CASALI, A. et al. Empregabilidade e educação : novos caminhos no mundo do trabalho. São Paulo : EDUC, 1997.

DRUCKER, P. As novas realidades. São Paulo : Pioneira, 1993.

ESMAN, M. Institution building research : the guiding concepts. Pennsylvania : Inter University Research Program in Institution Building, 1966.

ESMAN, M., BRUHNS, F. Institution building in national development : in approach to individual - social change in transactional societies. Pittsburgh : University of Pittisburg, 1965.

HALL, R. H. Organizações : estruturas e processos. Rio de Janeiro : Prentice Hall do Brasil, 1984.

KLIKSBERG, B. Como transformar o Estado : para além de mitos e dogmas. Tradução de Florindo Villa-Alvarez e Helena Ferreira. Brasília : Enap, 1992.

. Um novo paradigma em gestão pública. Revista do Serviço Público, Brasília, v. 116, n. 2, p. 39-46, maio/jun. 1988.

LOURAU, R. A análise institucional. Petrópolis : Vozes, 1995.

MATTA, R. da. Carnavais, malandros e heróis : para uma sociologia do dilema brasileiro. 5. ed. Rio de Janeiro : Guanabara, 1990.

MOTTA, P. R. A Ciência e a arte de ser dirigente. Rio de Janeiro : Record, 1994.

. Transformação organizacional. Rio de Janeiro : Qualitymark, 1997.

SELZNICK, P. A liderança na administração : uma interpretação sociológica. Rio de Janeiro : FGV, 1971.

SOUZA, E. C. L. Escolas de Governo. In: ENCONTRO DA ANPAD, 21, Rio de Janeiro,1997. Anais... Rio de Janeiro : Anpad, 1997.

. Escolas de Governo do Cone Sul : estudo institucional do INAP (Argentina) e da ENAP (Brasil). Brasília, 1996. Tese (Doutorado) - Universidade de Brasília, Faculdade Latino-Americana de Ciências Sociais.

Recebido em 10 de setembro de 1998.

Eda Castro Lucas de Souza, doutora em Sociologia, na área de Políticas Públicas Comparadas, pela Faculdade Latino-Americana de Ciencias Sociais/Universidade de Brasília (Flacso/UnB), é professora adjunta da Faculdade de Educação, Departamento de Planejamento e Administração dessa universidade.

\section{Abstract}

The goal of this study is to analyse the institutionalizacion of the public policies for government administrators formation. To do so factors from institution building theory introduced in the Esman pattern were used, combined with other political, cultural and administrative factores peculiar to the brazilian state apparatus. Based on this theoretical foundation and adjusted to the public policies we dealt with the basic elements that make possible to verify the trends and their institutionalization process. Some difficulties were brought forward in the institutionalization process of these policies and some proposals were also recommended so that the policies start to have a social function, are accepted by the community, settle a relation system to be followed and influence its context, i.e., be institutionalized.

Key-Words: public policies, institutionalization, management training. 